\title{
Improving Health Consciousness and Life Skills in Young People Through Peer-Leadership in Thailand
}

\author{
Teerachote $\mathrm{C},{ }^{1}$ Kessomboon $\mathrm{P},{ }^{1}$ Rattanasiri A, ${ }^{1}$ Koju R ${ }^{2}$
}

${ }^{1}$ Department of Community Medicine

Khon Kaen University, Thailand

${ }^{2}$ Kathamndu University School of Medical Sciences

Dhulikhel Hospital, Kavre, Nepal

\section{Corresponding author}

Chanya Teerachote

Department of Community Medicine

Khon Kaen University, Thailand

Email: chanyaja@windowslive.com

\section{Citation}

Teerachote C, Kessomboon P, Rattanasiri A, Koju R. Improving Health Consciousness and Life Skills in Young People Through Peer-Leadership in Thailand. Kathmandu Univ Med J 2013;41(1):41-44.

\section{ABSTRACT}

\section{Background}

Peer leadership is widely recognized as an effective approach to health promotion and empowerment among people of similar ages, especially the youth. Such programs build peer leaders who in turn help empower the youths in their groups to improve their health and life skills related to health. Most previous studies have focused on the effectiveness of such activities in target groups but have neglected to effectively address and explore the transformations in peer leaders themselves.

\section{Objectives}

This descriptive study aimed to investigate the level of social change and health consciousness among student peer leaders in three Youth health promotion programs in Thailand: Friend's Corner, Smart Consumer and Volunteer Minded Young Dentists, and to compare them with the general students.

\section{Methods}

The study was conducted using a self-administered questionnaire, which was developed based on Tyree's Social Change Model of leadership, Gould's concept and Dutta-Bergman's concept. The study population comprised of 11th grade students $(N=660)$ from Kalasin Province in Thailand, 320 of whom were peer leaders.

\section{Results}

The findings revealed that the peer leaders scored higher than non peer leaders in all domains. Among the peer leaders, it was found that Volunteer Minded Young Dentists group had the highest scores in "controversy with civility", "social change agent" characteristics, "holistic health perceptions" and "responsibility for one's own health" regarding health consciousness.

\section{Conclusion}

The results of this study confirmed that the peer leadership approach can help young people to develop life skills through social transformation and increase health consciousness for better status of health in the community.

\section{KEY WORDS}

Consciousness, health, peer group, social change, youth 


\section{INTRODUCTION}

Adolescence is a critical period in human life and is important in developing the adult self. Blum RW and Nelson NK estimates that $70 \%$ of premature deaths among adults are due to behavior initiated during adolescence (smoking, illicit drug use, reckless driving), in addition to the future demographic changes in the proportion of youth population which lead them to grow up in impoverished environments. ${ }^{1}$ Such situations create greater challenges in promoting healthy development among the youth. ${ }^{2}$

Volunteering has been found to have a positive impact on young people's success and has helped reduce behavioral problems such as drug abuse, violence and unwanted pregnancy. ${ }^{2}$ In addition to personal gain, youth volunteers were found to have more positive attitudes toward society. Volunteers acquired social responsibility, had more knowledge about others in their community, improved their skills, and were more capable of decision making than non-volunteers. ${ }^{3,4}$

In Thailand, the health promotion program for young people has been taking place since 2001. Friends' Corner, Smart Consumer and Volunteer Minded Young Dentist are examples of them. Young people who are involved in these programs voluntarily perform as peer-leaders and implement their own projects in order to empower other young people to increase health promotion life style, have life skills against health risks, and provide qualified services to cope with social, behavioral and health problems. Their efforts are widely believed to be beneficial, not only for the community, but also for the individuals who are associated with them. However, little attention has been paid to the "Health Consciousness"and "Change Agent" developed from health-volunteer service in volunteer themselves. So, this study was conducted to examine the developmental outcomes in Peer-Leader from three types of health promotion programs and to compare the differences with the general students.

\section{METHODS}

This descriptive study was conducted in two schools within the catchment area of Kalasin hospital in Kalasin province from August-September 2010 with self-reported questionnaire. $11^{\text {th }}$ graders who met the inclusion criteria of this study were the target population (625 students: 344 female and 269 male). The peer leaders were classified according to their programs: Friends' Corner (FC, $\mathrm{n}=121$ ), Smart Consumer (SC, $\mathrm{n}=117$ ) and Volunteer Minded Young Dentist (VMYD, $n=94$ ) while non-peer leaders were classified as General (GEN, $n=188$ ).

The Self-reported questionnaire was divided into three parts: Part I included bio-demography of participants as: gender, parental status (lived together, divorced or separated, widowed), birth order, academic achievement, socio-economic status and an open-ended question asking the reason to participate in health program for youth. Part II and III consisted of questions to measure Health
Consciousness and Social Change Agent Characteristic, respectively.

Health Consciousness Measurement (HCM) was adapted from the concept of health consciousness of Gould's and Dutta Bergman 's and composed of four domains so as to measure health concern among young people. ${ }^{5}$ Social Change Agent Characteristic Measurement (SCAM) composed of six domains as a way to measure leadership outcomes of Social Change Agent Characteristic (SCAC) which adapted from Tyree M. ${ }^{6}$ The reliability coefficient of HCM and SCAM were found to be 0.68 and 0.82 respectively. Data was verified through double entry data using Epi Info6 and was analyzed by Statistical Package for the Social Sciences (SPSS) Version 17.

\section{RESULTS}

The results of the study showed that of the total students who participated in the study, $77.1 \%$ were females while $22.9 \%$ were males. $44.9 \%$ of them had GPA between 2.51 and 3.0 and $53.1 \%$ of them were the $1^{\text {st }}$ order in the family. A total of $79.3 \%$ of the subjects lived with their parents and $59.1 \%$ of them came from families with an average income of less than 10,000 per month.

The study shows that peer leaders coming from different groups scored differently in the health consciousness and social change leadership characteristic measurements. In the Health Consciousness measurement, Smart Consumer had the highest score on HCPRO (M = 8.64, SD =0.99) and HCCONS domains ( $M=7.95, S D=0.91$ ) while VolunteerMinded Young Dentist had the highest score on HCHOL (M $=9.62, \mathrm{SD}=0.79)$ and HCRES domains $(M=9.3, \mathrm{SD}=1.13)$. According to SCA, Friends'Corner had the highest score on SCSELF (M = 8.84, SD = 0.96) and SCCONG domains ( $M=$ $8.95, \mathrm{SD}=0.99$ ) while Volunteer-Minded Young Dentist had the highest score on SCCOMMIT (M = 7.81, SD = 0.95) $\operatorname{SCCONT}(M=9.43, \mathrm{SD}=1.01) \operatorname{SCCOM}(M=9.09, \mathrm{SD}=1.10)$ and SCCHANG domains $(M=9.4, S D=1.15)$. A significant relationship between Health Consciousness and Social Change Characteristic was found to exist in peer leaders. Moreover, peer leaders scored higher than non peer leaders in all domains.

(Note: HCPRO = Proactive health domain of Health Consciousness, $\mathrm{HCHOL}=\mathrm{Holistic}$ health perception domain of Health Consciousness, HCCONS =Health information consumption domain of Health Consciousness, HCRES=Personal health responsibility domain of Health Consciousness

SCSELF=Self consciousness domain of Social Change Agent characteristic, SCCONG=Congruence domain of Social Change Agent characteristic, SCCOMMIT=Commitment domain of Social Change Agent characteristic SCCONT=Controversy with civility domain of Social Change Agent characteristic, SCCOM=Community connectedness domain of Social Change Agent characteristic, SCCHANG = 
Table 1. Bio-demography of subjects.

\begin{tabular}{|c|c|c|c|c|c|}
\hline \multirow{2}{*}{$\begin{array}{l}\text { Informa- } \\
\text { tion }\end{array}$} & \multirow[t]{2}{*}{ Total } & \multicolumn{3}{|c|}{ Peer leaders } & \multirow{2}{*}{$\begin{array}{l}\text { Non Peer } \\
\text { leaders }\end{array}$} \\
\hline & & FC & SC & VMYD & \\
\hline \multicolumn{6}{|l|}{ Gender } \\
\hline Male & 201(39\%) & $36(43 \%)$ & $26(33 \%)$ & $35(40 \%)$ & 104(39\%) \\
\hline \multirow[t]{2}{*}{ Female } & $319(61 \%)$ & $47(57 \%)$ & $54(67 \%)$ & $52(60 \%)$ & $166(61 \%)$ \\
\hline & 520 & 83 & 80 & 87 & 270 \\
\hline \multicolumn{6}{|l|}{ GPA } \\
\hline$<2.5$ & & $14(17 \%)$ & $14(18 \%)$ & $9(10 \%)$ & $51(19 \%)$ \\
\hline $2.51-3.0$ & & $38(46 \%)$ & $45(56 \%)$ & $45(52 \%)$ & 105(39\%) \\
\hline 3.1-3.5 & & $25(30 \%)$ & $11(14 \%)$ & $19(22 \%)$ & $71(26 \%)$ \\
\hline$>3.5$ & & $6(7 \%)$ & $10(12 \%)$ & $14(16 \%)$ & $43(16 \%)$ \\
\hline \multicolumn{6}{|c|}{ Birth order } \\
\hline $1^{\text {st }}$ & & 47 & 39 & 50 & 95 \\
\hline $2^{\text {nd }}$ & & 33 & 38 & 32 & 126 \\
\hline $3^{\text {rd }}$ & & 2 & 3 & 4 & 46 \\
\hline$\geq 4^{\text {th }}$ & & 1 & - & 1 & 3 \\
\hline \multicolumn{6}{|c|}{ Status of parents } \\
\hline together & & 63 & 68 & 64 & 201 \\
\hline $\begin{array}{l}\text { sep. or } \\
\text { divorce }\end{array}$ & & 10 & 5 & 11 & 40 \\
\hline widow & & 10 & 7 & 12 & 29 \\
\hline \multicolumn{6}{|c|}{ Income per month } \\
\hline$\leq 10,000$ & & 52 & 41 & 38 & 178 \\
\hline $\begin{array}{l}10,001- \\
15,000\end{array}$ & & 20 & 26 & 16 & 32 \\
\hline $\begin{array}{l}15,001- \\
20,000\end{array}$ & & 6 & 12 & 31 & 54 \\
\hline$\geq 20,001$ & & 5 & 1 & 2 & 6 \\
\hline
\end{tabular}

Change domain of Social Change Agent characteristic).

\section{DISCUSSION}

The findings of an important question of the study, that is, the reason behind the participation in volunteer work was classified into three reasons: educational and career advancement, social and peer influences and parent, teacher and/or mentor encouragement. Educational and career advance being chosen as the reason does not come as a surprise considering the life stage of the subjects wherein they are eager to discover themselves. This finding is in agreement with Musick and Wilson which reported that volunteering can be considered as an investment in skills improving someone's standing on the labour market. ${ }^{7}$ Similarly, Safrit, Scheer and King suggested that volunteering can enhance young people's career exploration and be included as part of building a strong college application or job resume. ${ }^{8}$ They also suggested that young people are more willing to actively engage in mixed gender groups as this inter-gender peer interaction promotes positive peer pressure.

Peer leaders (volunteers) showed higher score than nonpeer leaders (non-volunteers) in the level of Social Change Agent Characteristic in this study. The level of Social Change Agent Characteristic ranged from 9.4 (SD = 1.15) on change domain to 7.81 (SD =.95) on commitment domain. Such high score in Social Change Agent Characteristic Measurement (SCAM) may mean that values and beliefs incorporated in the domains of this component fit to that of the peer leaders. Many of these SCAM domains are articulated with the vision and mission statement of their organization value, so they may already be familiar to them. For example, members of Volunteer Minded Young Dentist are emphasized on "the importance of hometown development" and "respect the difference", both of which were relevant to the "community connectedness" domain and "controversy with civility" domain in SC. This may have

Table 2. Health Consciousness (HC) and Social Change (SC) level among 3 types of Peer-Leaders and Non-Peer Leaders.

\begin{tabular}{|c|c|c|c|c|c|c|c|c|c|}
\hline \multirow{2}{*}{$\begin{array}{l}\text { Type } \\
\text { Domain }\end{array}$} & & \multicolumn{2}{|l|}{ FC } & \multicolumn{2}{|l|}{ SC } & \multicolumn{2}{|l|}{ VMYD } & \multicolumn{2}{|c|}{$\begin{array}{l}\text { Non } \\
\text { Peer leaders }\end{array}$} \\
\hline & & Mean & SD & Mean & SD & Mean & SD & Mean & SD \\
\hline \multirow{4}{*}{$\mathrm{HC}$} & HCPRO & 6.81 & 0.99 & 8.64 & 0.99 & 7.59 & 1.12 & 3.35 & 1.08 \\
\hline & $\mathrm{HCHOL}$ & 6.85 & 1.24 & 5.70 & 1.52 & 9.62 & 0.79 & 3.68 & 1.60 \\
\hline & HCCONS & 6.89 & 1.02 & 7.95 & 0.91 & 7.53 & 0.89 & 3.57 & 1.15 \\
\hline & HCRES & 6.65 & 1.17 & 5.38 & 1.11 & 9.30 & 1.13 & 4.48 & 4.83 \\
\hline \multirow{6}{*}{ SC } & SCSELF & 8.84 & 0.96 & 5.04 & 1.43 & 7.72 & 1.01 & 3.91 & 1.55 \\
\hline & SCCONG & 8.95 & 0.99 & 5.09 & 1.31 & 7.61 & 0.93 & 3.99 & 2.21 \\
\hline & SCCOMMIT & 6.92 & 1.14 & 5.26 & 1.41 & 7.81 & 0.95 & 4.05 & 1.40 \\
\hline & SCCONT & 6.79 & 1.12 & 5.15 & 1.51 & 9.43 & 1.01 & 3.83 & 1.58 \\
\hline & ScCOM & 6.81 & 1.28 & 5.10 & 1.65 & 9.09 & 1.10 & 3.88 & 1.86 \\
\hline & SCCHANG & 6.70 & 1.22 & 5.19 & 1.57 & 9.40 & 1.15 & 3.93 & 1.86 \\
\hline
\end{tabular}


been the reason behind peer leaders scoring higher than non-peer leaders. However, it is also possible that students whose beliefs and values are in alignment with the value may be predisposed to attend such organizations.

According to Leadership Identity Development Theory, the development of students' leadership identity begins with their deepening self-awareness (individual level) and increased sense of self-confidence and so they move into groups and/or societal levels. Haber $P$ and Komives SR proposed that there are dynamic interactions between individuals, groups, and societal levels that lead to the establishment of a leadership identity. ${ }^{9}$ Students may progress to groups and societal levels within the social change model of leadership without first reconciling individual level needs. Similar observations were found in the study as Volunteer Minded Young Dentist (VMYD) had the highest score in group level domains(organization commitment, community connectedness, controversy with civility, citizenship) and societal level (change) but had lower score in individual level domains (self consciousness, congruence).

In this study, peer leaders showed higher score than nonpeer leaders in every domain of Health Consciousness. All reported that volunteers have an ability to cope with their own illness. ${ }^{11-14}$ They are also capable of adopting healthy lifestyles and practices such as HIV prevention behaviors, physical activity and healthy levels of drinking. ${ }^{15-17}$ All the above mentioned characteristics show why the volunteers may have personal health responsibility better than non- volunteers. Volunteering leads to increase levels of life satisfaction and improve physical health which holds true for the peer leaders in this study as well. ${ }^{17}$

Limitations in the study need to be considered. Data collection was done face-to-face based on a questionnaire. While this may have led to higher rates of completion, it may also have introduced researcher's bias in process of data collection despite all efforts to minimize it. The measurement used in this study has rather high reliability (0.788-0.952 of Alpha-Cronbach's coefficient), delicate scale (ratio scale) and high response rate (96\%). Also, this study is a descriptive one, hence, generalizability and cause-effect directional indication maybe of concern.

\section{CONCLUSION}

This study has attempted to suggest that the feasible method of meeting adolescents' needs and at the same time aiming to promote health consciousness is to foster an atmosphere of youth-adult companionship as youth volunteer program.

\section{ACKNOWLEDGEMENT}

I would like to express my sincere gratitude to Dr. Pattapong Kessomboon and Dr. Amornrat Rattanasiri for providing unrelenting support and guidance in my work.

\section{REFERENCES}

1. Blum RW, Nelson NK. The health of young people in a global context. Journal Adolescent Health 2004; 35: 402-18.

2. Resnick MD. Protective factors, resiliency and healthy youth development. Adolesc Med 2000 ;11(1):157-65.

3. Schondel C, Boehm KE, Rose J, Marlowe A. Adolescent volunteers: An untapped resource in the delivery of adolescent preventive health care. Youth and Society 1995;27:123-35.

4. Hamilton SF, Fenzel LM. The impact of volunteer experience on adolescent development: Evidence of program effects. Journal of Adolescent Research 1988; 3: 65-80.

5. Hong H. Scale development for measuring health consciousness: Reconceptualization. In: Yamamura K. Proceedings of the 12th Annual international public relations research conference,2009 March11-14, Holiday Inn University of Miami; 2009. P. 212-33.

6. Tyree TM. Designing an instrument to measure the socially responsible leadership using the social change model of leadership [dissertration]. University of Maryland; 1998.

7. Musick MA, Wilson J. Volunteering and depression: The role of psychological and social resources in different age groups. Social Science and Medicine 2003; 56: 259-69.

8. Safrit RD, Scheer SD, King JE. Understanding seasons of service: Promoting Volunteerism Across The Life Span. The Journal of Volunteer Administration 2004; 19(3): 15-23.

9. Haber P, Komives SR. Predicting the individual value of the Social Change Model of Leadership Development: The role of college students' leadership and involvement experiences. Journal of Leadership Education 2009; 7(3): 133-66.

10. Hainsworth J, Barlow . Volunteer's experiences of becoming arthritis self-management lay leaders: It's almost as if I've stopped aging and started to get younger. Arthritis Rheumatism 2001; 45(4): 378-83.

11. Arnstein PM, Vidal. From chronic pain patient to peer: Benefits and risks of volunteering. Pain management nursing 2002; 3(3): 94-103.

12. Clarks S. Voluntary work benefits mental health: A life in the day2003; 7(1): 10-14.

13. Coppa K, Boyle FM. The role of self-helped group in chronic illness management: A qualitative study. Australian Journal of Primary Health 2003; 9(2-3): 68-74.

14. Thoits P, Hewitt LN. Volunteer work and well-being. Journal of health\&social behavior 2001; 42(2): 115-32.

15. Ramirez VJ, Brown AJ. Latinos'community involvement in HIV/AIDS: organizational and individual perspective on volunteering. AIDS Education and Prevention 2003; 15(1a): 90-104.

16. Librett JM, Yore M. Take pride in America's health: volunteering as a gateway to physical activity. American Journal of Health Education 2005; 36(1): 8.

17. Weitzman ER, Kawachi I. Giving means receiving: The protective effect of social capital on binge drinking on college campuses. American Journal of Public Health 2000; 90(12): 1936-39. 